\title{
Reduction of perchlorate using zero-valent titanium (ZVT) anode: reaction mechanism
}

\author{
Chunwoo Lee*1, Bill Batchelor ${ }^{2}$, Sung Hyuk Park ${ }^{3}$, Dong Suk Han \\ Ahmed Abdel-Wahab ${ }^{4}$ and Timothy A. Kramer \\ ${ }^{1}$ Doosan Hydro Technology, Inc., Tampa, FL 33619, USA \\ ${ }^{2}$ Zachry Department of Civil Engineering, Texas A\&M University, College Station, TX 77840, USA \\ ${ }^{3}$ Environmental \& Energy Research Team, GS Engineering \& Construction Research Institute, \\ Youngin-si, Kyunggi-do, 449-831, Republic of Korea \\ ${ }^{4}$ Chemical Engineering Program, Texas A\&M University at Qatar, Education City, \\ Doha, PO Box 23874, Qatar \\ ${ }^{5}$ Deceased
}

(Received February 21, 2012, Revised March 21, 2012, Accepted March 27, 2012)

\begin{abstract}
Here we show that perchlorate reduction during pitting corrosion of zero-valent titanium (ZVT) is likely caused by dissolved titanium species, especially Ti(II). Several possible mechanisms were suggested based on the literature and were evaluated based on experimental observations. Direct reduction of perchlorate on the bare metal of the ZVT electrode was thermodynamically infeasible due to the high anodic potential that was applied. Other potential mechanisms were considered such as reduction by small ZVT metal particles released from the electrode and direct reduction on the oxide layer of the electrode where potential was sufficiently reduced by a high ohmic potential drop. However, these mechanisms were not supported by experimental results. The most likely mechanism for perchlorate reduction was that during pitting corrosion, in which ZVT is partially oxidized to form dissolved ions such as Ti(II), which diffuse from the electrode surface and react with perchlorate in solution. This mechanism is supported by measurements of the dissolution valence and the molar ratio of ZVT consumed to perchlorate reduced $\left(\Delta \mathrm{Ti}(0) / \Delta \mathrm{ClO}_{4}{ }^{-}\right)$. The results shown in this study demonstrate that ZVT undergoing pitting corrosion has the capability to chemically reduce perchlorate by producing dissolved $\mathrm{Ti}$ (II) and therefore, it has the potential to be applied in treatment systems. On the other hand, the results of this research imply that the application of ZVT undergoing pitting corrosion in treatment systems may not be feasible now due to several factors, including material and electricity costs and possible chloride oxidation.
\end{abstract}

Keywords: perchlorate; reduction; corrosion; zero-valent titanium; reductant

\section{Introduction}

Perchlorate is a threat to public health through water but also food. However, there is no effective chemical treatment process which can destroy perchlorate found in groundwater and surface water. Thus, there is growing interest in developing effective technologies, especially chemical treatments, to completely destroy trace levels of perchlorate present in drinking and groundwater. Recently, the

*Corresponding author, Manager of Process Engineering, E-mail: clee@doosanhydro.com 
U.S. Environmental Protection Agency (EPA) reported that perchlorate should be considered as a contaminant to be listed on the Safe Drinking Water Act (SDWA) criteria because perchlorate is frequently found in public water systems with levels that could pose a public health concern (EPA 2012). Perchlorate has been found in drinking water or groundwater because of contamination from the anthropogenic activity including manufacture or use it, or disposal of rockets, fireworks, and ammunition (Srinivasan and Sorial 2009).

Applications of zero-valent metals are familiar technologies for reducing organic and inorganic contaminants in natural water. Physicochemical sorption and chemical reduction are the mechanisms by which zero-valent metal technologies abate contaminants. In the chemical reduction mechanism, the contaminant is reduced by direct contact with metal surface or by contact with partially oxidized metal ions released from the metal surface, which is generally promoted via pitting corrosion. Several studies have reported that the presence of chloride $\left(\mathrm{Cl}^{-}\right)$, pretreatment with acid, or pretreatment with ultrasound improved treatment efficiency by stimulating pitting corrosion (Farrell et al. 2000, Gaspar et al. 2002, Geiger et al. 2002, Hernandez et al. 2004, Scherer et al. 1999). Moreover, studies have reported that pitting corrosion is involved in reduction of perchlorate by zero-valent metals (Gu et al. 2006, Lien et al. 2010, Wang et al. 2010, Wang et al. 2008, Wang et al. 2007, Wang et al. 2009). Prinz and Strehblow (1998) reported perchlorate reduction by zerovalent iron at pitting sites during experiments that measured its pitting potential. They measured the increase in the concentration of chloride over time at the pitting site using X-ray Photoelectron Spectroscopy. Aluminum was reported to reduce perchlorate by a mechanism involving an unstable aluminum ion $\left(\mathrm{Al}^{+}\right)$that was formed during anodic dissolution of $\mathrm{Al}(0)$ through the pitting corrosion (Szklarska-Smialowska 1986). Reduction of perchlorate was also observed at the pitting site during electropolishing of titanium in acetic acid solution that contained perchlorate (Mathieu and Landolt 1978, Mathieu et al. 1978). Chloride, which is the final reduction product of perchlorate, was found in the solution and in the oxide film. In the oxide film, the chloride concentration increased at locations closer to the interface between titanium metal and the oxide film. The presence of chloride was explained by its production during reduction of perchlorate at discrete sites near the metal surface that were formed through pitting corrosion.

Research has investigated the influence of electrochemical (potential, current, and surface area of ZVT) and environmental parameters (solution $\mathrm{pH}$ ) on perchlorate reduction at pitting sites on ZVT electrodes (Lee et al. 2011). Results showed that rates of perchlorate reduction were strongly dependent on the electrochemical parameters, especially current. In this study, perchlorate reduction mechanisms are proposed and evaluated using visual observations, scanning electron microscopy (SEM), and measurement on titanium ions for perchlorate. Additional evaluations were based on X-ray diffraction (XRD) analysis of ZVT oxidation products, dissolution valence of ZVT, and molar ratio of consumed ZVT to reduced perchlorate. Furthermore, a mechanism for perchlorate reduction at the pitting site on ZVT was proposed in an effort to understand perchlorate reduction at the pitting site.

\section{Materials and method}

\subsection{Chemicals}

Sodium perchlorate $(98.0+\%$, Aldrich) was used in this study as a source of perchlorate. $1000 \mathrm{mg} / \mathrm{L}$ of stock solution was prepared by dissolving sodium perchlorate with deionized water. 
Appropriate perchlorate concentration in the electrochemical reactor was obtained by spiking the calculated amount of the stock solution to the reactor. Ti(0) sheets $(99.97 \%)$ were purchased from ESPI Corp. Inc. and cut to appropriate sizes for the experiments. The Ti(0) sheets were washed with acetone to remove organic impurities and rinsed several times with deionized water, then dried in room temperature and stored in a desiccator.

\subsection{Perchlorate reduction with Ti(II) and Ti(III) containing solution}

Ti(III) solutions of 100 and $200 \mathrm{mM}$ were prepared by dissolving $\mathrm{TiCl}_{3}(99.9 \%$, Aldrich) in $1 \mathrm{~N}$ and $5 \mathrm{~N} \mathrm{HCl}$ (Fisher). A Ti(II) solution was prepared by a modification of the method reported by Kölle (2003) and the modified method is based on the following reaction.

$$
2 \mathrm{Ti}^{3+}+6 \mathrm{~F}^{-} \rightarrow\left[\mathrm{TiF}_{6}\right]^{2-}+\mathrm{Ti}^{2+}
$$

A solution containing $\mathrm{KF}\left(99.0 \%\right.$, ACS grade, EM) $(600 \mathrm{mM})$ and $\mathrm{TiCl}_{3}(200 \mathrm{mM})$ in $1 \mathrm{~N}$ and $5 \mathrm{~N} \mathrm{HCl}$ was prepared to generate a solution that would contain $100 \mathrm{mM} \mathrm{Ti}$ (II) if the reaction 1 were to go to completion. Absorption spectrums of Ti(II) and Ti(III) were measured using a UVVIS spectrophotometer (Hewlett Packard G1103A).

Batch kinetic experiments were conducted in $250-\mathrm{mL}$ polyethylene bottles where the calculated amount of the stock solution of perchlorate was added to the bottles containing the prepared aqueous titanium solution (Ti(II) or Ti(III)). The initial concentration of perchlorate in the bottle was $1.18 \mathrm{mM}$ together with $100 \mathrm{mM}$ or $200 \mathrm{mM}$ Ti(III), or $100 \mathrm{mM}$ Ti(II). Then, all bottles were mixed using a rotator for reduction of perchlorate. At specified sample time, $1 \mathrm{~mL}$ of sample was taken, transferred to $10-\mathrm{mL}$ test tube, and stored inside an anaerobic chamber before the analysis of perchlorate. All experiments with $\mathrm{Ti}(\mathrm{II})$ and $\mathrm{Ti}(\mathrm{III})$ were conducted using an anaerobic chamber filled with a mixed gas containing 5\% hydrogen and $95 \%$ nitrogen. The deionized water was purged with $99.99 \%$ argon gas for 2 hours and stored in an anaerobic chamber until use. All Ti(II) and Ti(III) solutions were prepared fresh and discarded after $12 \mathrm{hrs}$.

\subsection{Determinations of dissolution valence and molar ratio of $\Delta \mathrm{Ti}(0) / \Delta \mathrm{ClO}_{4}{ }^{-}$}

Experiments to determine the dissolution valence of ZVT and the molar ratio of ZVT consumed to perchlorate consumed $\left(\Delta \mathrm{Ti}(0) / \Delta \mathrm{ClO}_{4}^{-}\right)$were conducted with an electrochemical cell having two ZVT electrodes (anode and cathode) and operated at constant current. The constant current was supplied by a DC power supply (Kenwood, Model PW18-1.8AQ). The reactor system (anode and cathode sizes, materials, and effective reactor volume) was the same as described in previous study for experiments to determine the pitting potential (Lee 2007). The weight loss of the ZVT anode was determined by measuring the weight of ZVT before and after experiments. After experiments, ZVT was washed with tap water, and carefully scrubbed with a plastic brush to remove precipitates from the ZVT surface. Washing and brushing were repeated several times. ZVT was rinsed several times with deionized water and dried at room temperature before measuring its weight.

\subsection{Analytical methods}

Concentrations of $\mathrm{ClO}_{4}^{-}, \mathrm{ClO}_{3}^{-}, \mathrm{ClO}_{2}^{-}$, and $\mathrm{Cl}^{-}$were analyzed using a Dionex 500 ion 
chromatograph equipped with a 4-mm Dionex AS-16 analytical and guard column. The eluent concentration, gradient operation, and injection sample loop size were the same as in a previous study (Moore et al. 2003), except that $\mathrm{NaOH}$ was used instead of $\mathrm{KOH}$. Concentrations of perchlorate less than $1 \mathrm{mg} / \mathrm{L}$ were analyzed isocratically with a $1.00 \mathrm{~mL} \mathrm{~min}$ m $^{-1}$ flow of $50 \mathrm{mM}$ $\mathrm{NaOH}$ as eluent and a $1000-\mu \mathrm{L}$ injection sample loop. The compositions of the oxidation byproducts of ZVT were analyzed using XRD with a Riga automated diffractometer using $\mathrm{Cu} \mathrm{K} \alpha$ radiation. Samples were carefully collected after each experiment and washed several times with deionized water (shake for 5-minutes, separate by centrifugation, decant supernatant). After washing, the samples were placed in a vacuum drying oven held at $30^{\circ} \mathrm{C}$ (Thelco Inc, Model 19) for one week and stored in caped bottles until analysis.

\section{Results and discussion}

\subsection{Possible mechanisms for perchlorate reduction}

In zero-valent metal systems, it has been shown that pitting corrosion enhances the rate of contaminant removal. The localized breakdown of the surface oxide film due to pitting corrosion promotes direct reduction by increasing the contact of contaminants to the exposed bare metal surface (Gaspar et al. 2002, Gotpagar et al. 1999, Hernandez et al. 2004, Moore et al. 2003). However, the direct reduction by the underlying ZVT is not an appropriate mechanism to explain perchlorate reduction in this study. The standard electrode reduction potential for $\mathrm{ClO}_{4}{ }^{-} / \mathrm{Cl}^{-}$is 1.29 $\mathrm{V}$ (Emsley 1991) so substantial reduction of perchlorate to form chloride would not occur at the potentials needed to induce pitting corrosion of ZVT $(>12.8 \mathrm{~V})$.

There are some studies that have reported similar anomalous behavior of a reduction of a dissolved compound occurring during anodic dissolution of other metals. Systems containing $\mathrm{Al}(0)$, $\operatorname{Be}(0), \operatorname{Ti}(0)$, and $\mathrm{Zn}(0)$ showed hydrogen evolution when these metals were anodically polarized by imposition of an external potential or by contacting them with more noble metals (Beck 1973a, b, Drazic and Popic 2005, James 1974). The potentials applied to the anode were above the $\mathrm{H}^{+} / \mathrm{H}_{2}$ equilibrium potential, so the behavior appeared to contradict thermodynamics. Several mechanisms have been suggested to explain these anomalous behaviors observed during electrochemical dissolution of metals. They include ejection of particles of bare metal during disintegration of the electrode surface, a high potential drop caused by increased resistance of films, and formation of transitory and unexpected partially oxidized metal ions (Beck 1973a, b, Drazic and Popic 2005, James 1974). The first and third mechanisms would result in hydrogen production away from the electrode surface and the second mechanism would result in hydrogen production at the external surface of the film attached to the electrode.

\subsection{Bare titanium metal particle ejection}

Ejection of bare metal particles during metal corrosion by imposition of an external potential was observed in the experiments using $\operatorname{Be}(0), \operatorname{Mg}(0), \mathrm{Zn}(0), \mathrm{Cd}(0)$, and $\mathrm{Al}(0)$. The ejected metal particles were either dispersed in solution as particles with diameters of the order of $10^{-1} \mu \mathrm{m}$ or associated with metal precipitates (Drazic and Popic 2005, James 1974). In order to investigate possible ZVT particle ejections, optical microscopic observations were conducted to identify ZVT 


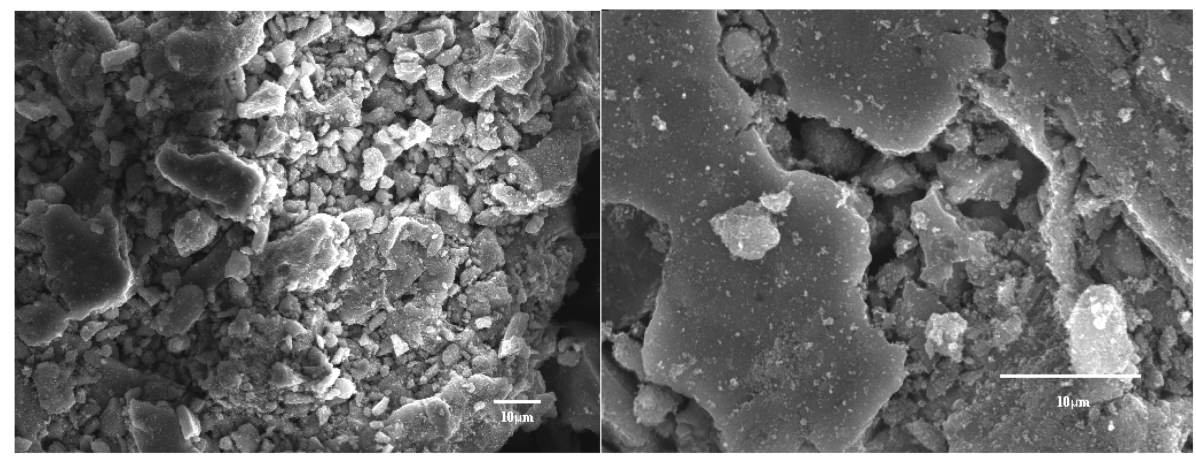

Fig. 1 SEM images of the precipitate produced at $100 \mathrm{~mA}$ : (left) $\times 1000$; (right $) \times 3000$

particles dispersed in solution. Analysis by SEM and XRD were also conducted to identify particles associated with the precipitate. The optical microscopic observations found that no ZVT particles were dispersed in the solution (data not shown). The precipitates were observed using SEM and no ZVT particles were found in the precipitate as shown in Fig. 1.

Instead, dark gray ZVT particles were observed by eye on the bottom of the reactor after long hours of operation. Some of these gray particles were over $1 \mathrm{~mm}$. These particles were probably disintegrated debris from ZVT edges during pitting corrosion. It is believed that these particles are not responsible for the perchlorate reduction due to their larger size and color. ZVT is always covered by a thin titanium oxide film that is transparent, thus ZVT has a metallic gray color. However, as the oxide film on ZVT grows in thickness by imposition of electrochemical potential or oxidizing chemicals, the oxide film reflects different wavelengths of light and produces different colors (Delplancke et al. 1982, Delplancke and Winand 1988, Gaul 1993, Hrapovic et al. 2001). In this study, long hours of imposing an electrochemical potential on ZVT changed its color from a metallic gray to dark gray due to growth of the oxide film. This dark gray color was identical to that of larger ZVT particles found in the precipitate. If micro-scale ZVT particles without oxide film are ejected from the pitting site, they would be immediately oxidized due to its unstable thermodynamic nature of bare ZVT. However, if these micro-scale ZVT particles are not completely oxidized, then they would be passivated by the formation of surface oxide film and they could be embedded in oxide precipitates which would make them undetectable by microscopic observation. Previous studies reported that XRD can detect the presence of metallic ZVT even it was covered by surface oxide film that was generated by electrochemical anodization and thermal oxidation (Basame and White 2000, Guleryuz and Cimenoglu 2004, Park et al. 2007, Yan and Wang 2004). Thus, the precipitates produced in $1 \mathrm{mM}$ of perchlorate solutions at different currents were collected and analyzed using XRD to investigate the possible presence of metallic ZVT particles associated with precipitates.

Fig. 2 shows that the dried precipitates contain mainly $\mathrm{TiO}_{2}$ in the form of synthetic anatase (tetragonal $\mathrm{TiO}_{2}$ ) and brookite (orthorthombic $\mathrm{TiO}_{2}$ ). No metallic ZVT was observed in the XRD analysis. However, if ejected bare ZVT particles are completely oxidized or small amounts of metallic ZVT remained in the precipitate, the XRD analysis could be inconclusive in providing evidence of the presence of ZVT particles associated with precipitates. Thus, results of XRD analysis cannot be used to completely rule out ejection of ZVT particles as a possible mechanism to describe perchlorate reduction at the pitting sites. 


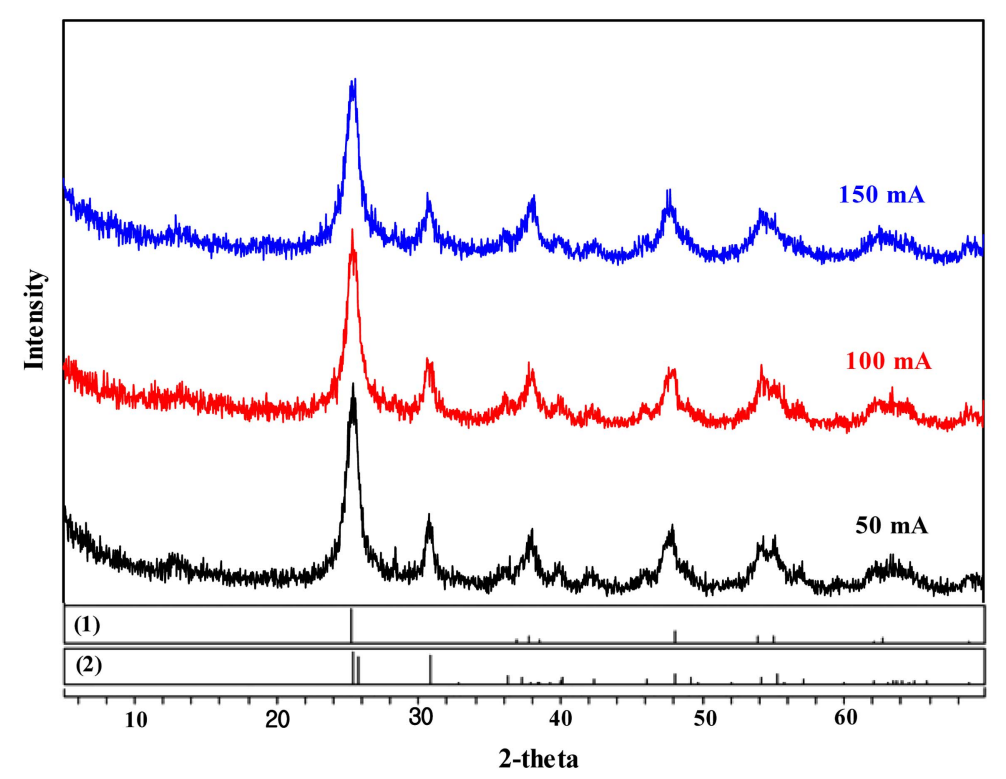

Fig. 2 XRD analysis of precipitates produced under different current conditions. (1) synthetic anatase; (2) brookite

\subsection{High ohmic drop}

During electropolishing of ZVT in a mixture of perchloric and acetic acids, it was observed that perchlorate was reduced to chloride in spite of imposed potentials that apparently would make that reaction thermodynamically infeasible (Mathieu and Landolt 1978). This might be explained by development of lower potential than standard electrode reduction potential for $\mathrm{ClO}_{4}^{-} / \mathrm{Cl}^{-}$at the pitting site because of the high ohmic resistance of the salt film. Several studies reported that during pitting corrosion the bottom of the pit is covered by a salt film consisting of metal salts or metal oxy-anion salts (Alkire et al. 1978, 1973a, Beck 1973b, Beck 1984, Beck and Alkire 1979, Clerc and Landolt 1988, Grimm et al. 1992, Isaacs 1973, Mankowski and Szklarskasmialowska 1977, Okada 1984, Sridhar and Dunn 1997). This salt film is produced by massive dissolution of the metal at the pit, super-saturation of dissolved metal cations, and their precipitation at the bottom of the pit. For titanium in halide solutions, the composition of the salt film was titanium tetrahalide or oxy-halide (Beck 1973a). Beck (1973b) calculated a potential drop across the salt film formed in a pit on ZVT in $\mathrm{HBr}$ solution that was 80 to $125 \%$ of the applied potential. However, his calculation was based on the assumption that the potential inside the pit was negative compared to the $\mathrm{H}^{+} / \mathrm{H}_{2}$ equilibrium potential. This was based on observations of hydrogen gas evolution. This assumption was used to calculate the potential drop across the salt film by simply subtracting summations of open circuit potential, ohmic potential drop outside of the pit, and ohmic potential drop inside pit from the applied potential. Thus, the calculated potential drop might not represent the actual potential drop caused by the salt film. Moreover, there are other studies that contradict this result by reporting that the potential drop by the salt film is very small (Danielson 1988, Hunkeler et al. 1987, Palit and Gadiyar 1987, Strehblow and Ives 1976). For example, the potential drop caused by 
the salt film near zirconium electrodes was only $0.03 \mathrm{~V}$ when the applied potential was $0.2 \mathrm{~V}$ (Palit and Gadiyar 1987) and potential drop for nickel was $0.5 \mathrm{~V}$ when the applied potential was $0.9 \mathrm{~V}$ (Danielson 1988). In this study, potentials over $12.7 \mathrm{~V}$ were imposed to develop pitting corrosion on ZVT. Thus, it is questionable that the salt film could cause the potential drop below the $\mathrm{ClO}_{4}^{-} / \mathrm{Cl}^{-}$ equilibrium potential at pitting site on ZVT. Other possible causes for a large potential drop in the pit are formation of solid corrosion products, accumulation of hydrogen gas, and existence of colloids (Palit and Gadiyar 1987, Pickering 1987). Among them, solid corrosion product would more likely develop a potential drop that results in potential below the $\mathrm{ClO}_{4}{ }^{-} / \mathrm{Cl}^{-}$equilibrium potential at pitting site on ZVT. Additionally, several other studies reported that direct cathodic reduction of perchlorate is a very sluggish reaction on other metal electrodes (Lang and Horanyi 2003). Therefore, it is believed that perchlorate reduction by the high ohmic drop is not likely to be the mechanism of observed perchlorate reduction.

\subsection{Formation of titanium metal ions}

Formation of partially oxidized metal ions is the most widely accepted hypothesis to describe the anomalous behavior of compounds being reduced at metal electrodes during anodic polarization (Drazic and Popic 2005, James 1974). ZVT could produce two partially oxidized ions $\left(\mathrm{Ti}^{2+}\right.$ and $\mathrm{Ti}^{3+}$ ) that would be intermediates before formation of the final product of Ti(IV). Ti(III) can exist in solid phases such as titanium halide $\left(\mathrm{Ti}(\mathrm{X})_{3}\right.$, where $\mathrm{X}=\mathrm{F}, \mathrm{Cl}, \mathrm{Br}$, or I) and titanium oxide $\left(\mathrm{Ti}_{2} \mathrm{O}_{3}\right)$ or in the aqueous phase as $\mathrm{Ti}^{3+}$ (Cotton et al. 1995, Webelements periodic table 2007). Ti(II) is not common, but its existence has been shown by the presence of titanium halide $\left(\operatorname{Ti}(\mathrm{X})_{2}\right.$, where $\mathrm{X}=\mathrm{F}$, $\mathrm{Cl}$, Br, or I), titanium hydride $\left(\mathrm{TiH}_{2}\right)$, and titanium oxide (TiO) in solid phases (Webelements periodic table 2007). Furthermore, several studies reported that Ti(III) can rapidly reduce perchlorate compared to common metal reductants (Amadei and Earley 2001, Earley et al. 2000, Espenson 2000, Ivanenko et al. 2001). However, the presence of Ti(II) in the aqueous phase and reaction with perchlorate are not well documented. Only a few studies have observed the formation of greenishbrown or greenish-yellow solutions believed to contain Ti(II) during dissolution of TiO by solutions of non-oxidizing acids or dissolution of ZVT with solutions of acids containing excess fluoride $\left(\mathrm{F}^{-}\right)$ (Kölle and Kölle 2003, Pourbaix 1966).

Visual observations were made to identify the presence of transitory titanium metal species in solutions during ZVT dissolution. However, there was no indication of Ti(II) or Ti(III) being present in the solution during experiments, because there were no greenish-yellow (Ti(II)) or violet (Ti(III)) colors observed. Microscopic observations also failed to show the existence of any solid compounds of $\mathrm{Ti}(\mathrm{II})$ and $\mathrm{Ti}(\mathrm{III})$ that are black and violet colors when they form either hydride or oxide (Webelements periodic table 2007). However, it is possible that ZVT could undergo dissolution to form $\mathrm{Ti}(\mathrm{II})$ and $\mathrm{Ti}(\mathrm{III})$ that exists only near the surface of ZVT. An especially likely location would be inside the pitting sites.

In order to investigate whether perchlorate is reduced by partially oxidized titanium ions, experiments were carried out with solutions of Ti(II) and Ti(III). Fig. 3 shows absorption spectrums of Ti(II) and $\mathrm{Ti}$ (III) solutions. The Ti(II) solution showed the same green color and the same absorption spectrum with maximums at 430 and $660 \mathrm{~nm}$ as has been reported (Kölle and Kölle 2003). The Ti(III) solution shows an absorption band at $505 \mathrm{~nm}$, which is similar to that reported by previous studies (Earley et al. 2000). The concentration of $\mathrm{H}^{+}$had a negligible effect on the absorption spectrum of $\mathrm{Ti}(\mathrm{II})$, but the absorption peak at $505 \mathrm{~nm}$ for $\mathrm{Ti}(\mathrm{III})$ was slightly shifted to longer 


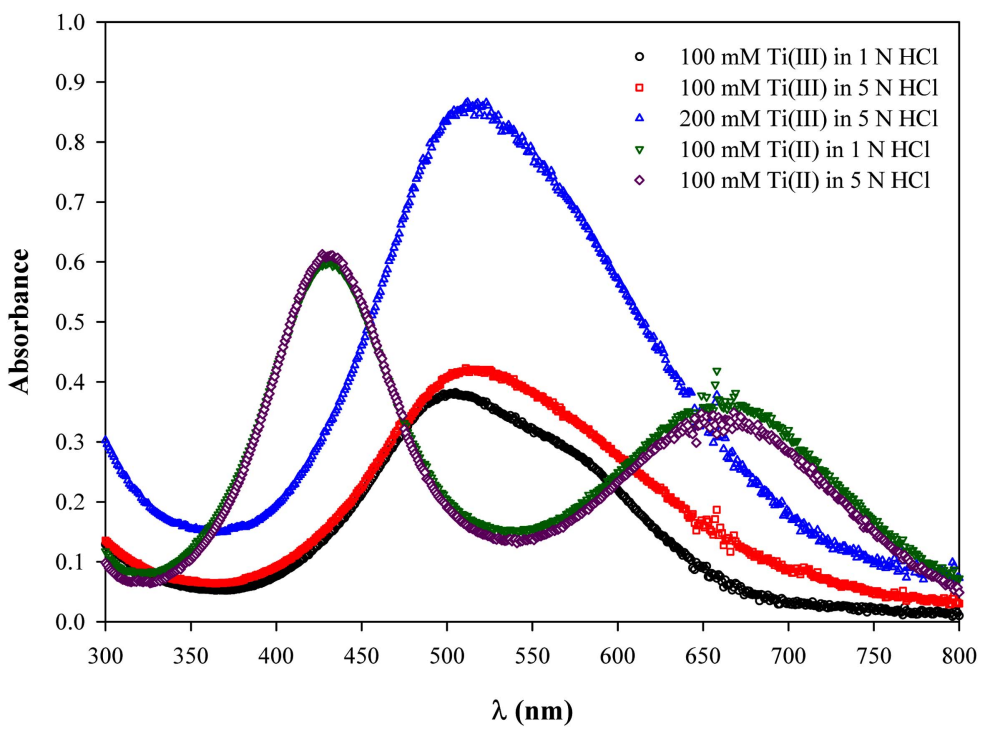

Fig. 3 Adsorption spectrums of Ti(II) and Ti(III) solutions

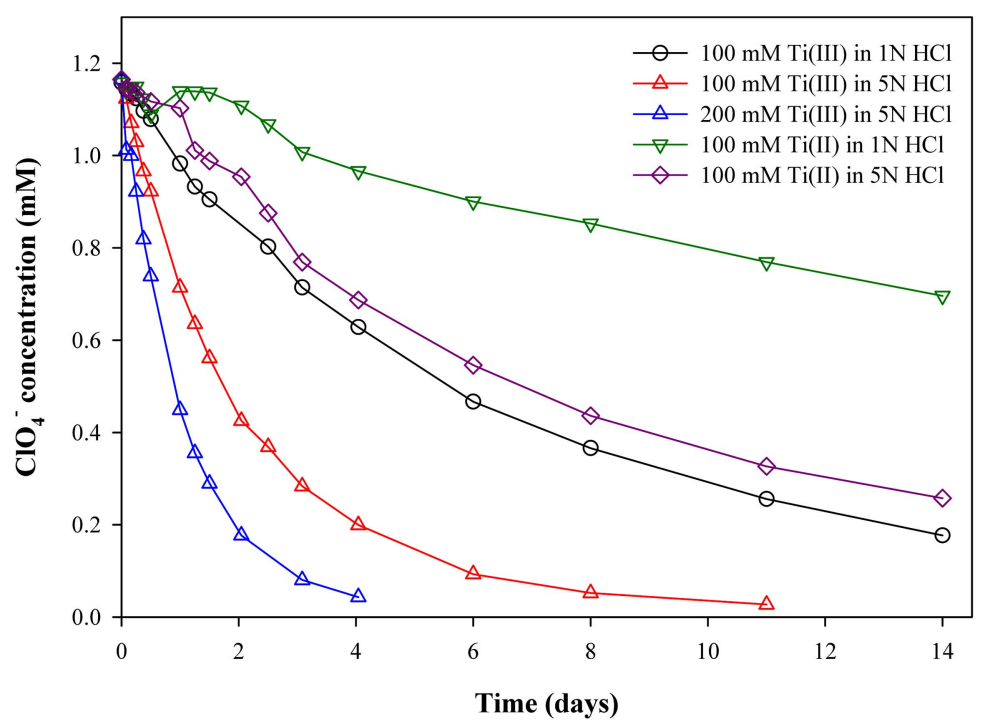

Fig. 4 Perchlorate reduction with Ti(II) and Ti(III)

wavelength at higher concentrations of $\mathrm{H}^{+}$. Fig. 4 shows how concentrations of perchlorate were reduced in solutions of Ti(II) and Ti(III). There is a higher rate of perchlorate reduction with Ti(III) than with $\mathrm{Ti}(\mathrm{II})$ and higher rates with both were observed at higher concentrations of $\mathrm{H}^{+}$.

Experiments shown in previous study were conducted with an initial $\mathrm{pH}$ of 6.0 and a final $\mathrm{pH}$ of 7.5 (Lee 2007). Within this $\mathrm{pH}$ range, it is expected that perchlorate reduction by Ti(II) and Ti(III) would be much slower than shown in Fig. 4. As expected, pitting corrosion produces lower $\mathrm{pH}$ 
conditions inside the pit that could promote the reaction rate. Pitting corrosion occurs in a localized area in which substantial amounts of metal can dissolve. The dissolved metal ions undergo hydrolysis reactions that develop a high concentration of $\mathrm{H}^{+}$inside of the pit (Fontana 1986, Szklarska-Smialowska 1986). Dissolution of ZVT would produce Ti(IV) as the primary product, whether it is formed by oxidation of ZVT at the electrode or by oxidation of transitory species such as Ti(II) and Ti(III). The hydrolysis of Ti(IV) would produce $\mathrm{H}^{+}$ions as shown by the following

$$
\begin{gathered}
\mathrm{Ti}^{4+}+\mathrm{H}_{2} \mathrm{O} \rightarrow \mathrm{TiO}^{2+}+2 \mathrm{H}^{+} \\
\mathrm{TiO}^{2+}+\mathrm{H}_{2} \mathrm{O} \rightarrow \mathrm{TiO}_{2}+2 \mathrm{H}^{+}
\end{gathered}
$$

These hydrolysis reactions would maintain the lower $\mathrm{pH}$ in the pit during the pitting corrosion of ZVT. Furthermore, there is some evidence in the literature that suggests that concentrations of anions such as perchlorate are dramatically increased inside pits because of the need to maintain electro-neutrality during production of metal cations such as $\mathrm{Ti}^{4+}$ and $\mathrm{TiO}^{2+}$ (Fontana 1986, Szklarska-Smialowska 1986). Measurements of chloride concentrations in pits developed on a stainless austenitic steel showed that chloride concentrations accumulated in the pits at concentrations up to 20 times higher than in the external solution (Mankowski and Szklarskasmialowska 1977). Thus, pitting corrosion of ZVT could produce not only lower $\mathrm{pH}$, but also higher perchlorate concentrations in the pits which could induce faster perchlorate reduction. However, it is hard to determine whether $\mathrm{Ti}(\mathrm{II})$ or $\mathrm{Ti}(\mathrm{III})$ is responsible for perchlorate reduction at the pitting site of ZVT based on results presented in Fig. 4.

Two other measurements were made in order to further evaluate the role of Ti(II) and Ti(III) in perchlorate reduction. One measured the dissolution valence using Faraday's law and the other calculated the molar ratio of ZVT consumed to perchlorate reduced. Faraday's law states that the amount of chemical change at the electrode is proportional to the total quantity of electric charge passed. Application of this law allows calculation of the titanium dissolution valence using the measured amount of ZVT lost by reaction

$$
n_{\mathrm{Ti}}=\frac{\mathrm{Mw}_{\mathrm{Ti}} Q_{t}}{\Delta \mathrm{M}_{\mathrm{Ti}} F}
$$

where $n_{\mathrm{Ti}}$ represents the dissolution valence of titanium, $\Delta \mathrm{M}_{\mathrm{Ti}}$ is loss of mass of ZVT $(g), \mathrm{Mw}_{\mathrm{Ti}}$ is atomic weight of titanium, and $F$ is Faraday's constant $(=96,485 \mathrm{C} / \mathrm{mole})$. The total quantity of electric charge passed, $Q_{\mathrm{t}}(\mathrm{C})$, is defined as

$$
Q_{t}=\int I d t
$$

where $I$ represents current $(A)$, and $t$ is time $(s)$. Three chemical reactions were assumed to be possible at the ZVT electrode: titanium dissolution, water oxidation, and chloride oxidation. However, the charge consumed by the water and chloride oxidations was assumed to be negligible for following reasons. Vigorous formation of gas bubbles at the ZVT anode would be expected if oxygen were being formed, but gas was observed during only the initial stage of an experiment (Lee 2007). After pitting corrosion began, formation of gas bubbles on the ZVT electrode diminished with only small gas bubbles being observed and these bubbles have been identified by others as being hydrogen gas (Beck 1973a, Palit and Gadiyar 1987). Therefore, charge consumption 
by water oxidation would be negligible in the experiments after pitting corrosion had begun. The amounts of electrical charge consumed by chloride oxidation were calculated using the amounts of $\mathrm{Cl}$ lost from solution

$$
Q_{\mathrm{CI}}=\frac{\Delta \mathrm{M}_{\mathrm{CI}}}{\mathrm{MW}_{\mathrm{CI}}} n_{\mathrm{CI}} \mathrm{F}
$$

where $Q_{\mathrm{Cl}}$ represents electrical charge consumption by chloride oxidation, $\Delta \mathrm{M}_{\mathrm{Cl}}$ is loss of mass of $\mathrm{Cl}(\mathrm{g})$, $\mathrm{Mw}_{\mathrm{Cl}}$ is atomic weight of chlorine, and $n_{\mathrm{Cl}}$ is the number of electrons transferred per chlorine molecule that undergoes oxidation $(=1)$. The chlorine loss $(\mathrm{mol})\left(\Delta \mathrm{M}_{\mathrm{Cl}} / \mathrm{Mw}_{\mathrm{Cl}}\right)$ was calculated by an elemental balance on chlorine

$$
\frac{\Delta \mathrm{M}_{\mathrm{CI}}}{\mathrm{MW}_{\mathrm{CI}}}=\left(\left[\mathrm{CIO}_{4}^{-}\right]_{\mathrm{i}}+\left[\mathrm{CI}^{-}\right]_{\mathrm{i}}-\left[\mathrm{CIO}_{4}^{-}\right]_{\mathrm{f}}-\left[\mathrm{CI}^{-}\right]_{\mathrm{f}}\right) \times V_{R}
$$

where $\left[\mathrm{ClO}_{4}{ }^{-}\right]_{\mathrm{i}}$ and $\left[\mathrm{Cl}^{-}\right]_{\mathrm{i}}$ represent the initial molar concentrations of perchlorate and chloride, $\left[\mathrm{ClO}_{4}{ }^{-}\right]_{\mathrm{f}}$ and $\left[\mathrm{Cl}^{-}\right]_{\mathrm{f}}$ are the molar concentrations of perchlorate and chloride measured at the final sampling time, and $V_{R}$ is effective solution volume. Other possible products containing chloride such as chlorate and chlorite are not included in Eq. (7), because they were not detected in substantial concentrations. Table 1 shows electric charge consumption by chloride oxidation relative to total electric charge applied under various experimental conditions. The electric charge consumptions by chloride oxidation were calculated to be less than $4 \%$ of total electric charge applied, even in higher chloride concentration solutions. Thus, the electric charge consumption by chloride oxidation was assumed to be negligible compared to titanium dissolution, so the titanium dissolution valence was calculated only considering titanium weight loss.

Table 2 shows the dissolution valence of titanium calculated in experiments at various concentrations of perchlorate and chloride. Experiments at each condition were replicated at least three times. As the concentration of perchlorate increases from $1 \mathrm{mM}$ to $500 \mathrm{mM}$, the dissolution valence decreases from $3.77 \pm 0.09$ to $2.67 \pm 0.01$. However, when only chloride is present, the dissolution valence is maintained around +4 , and is independent of the concentration of chloride. These results show that the valence of ZVT dissolution depends on whether the solution contains perchlorate or chloride, and concentration of perchlorate.

Additionally, Table 2 implies that ejection of bare ZVT particles may not occur at the pitting site. If bare ZVT particle were ejected at the pitting site, $\Delta \mathrm{M}_{\mathrm{Ti}}$ in Eq. 4 would be increased and dissolution valence should be less than +4 in chloride solutions. However, the constant dissolution

Table 1 Electric charge consumptions by chloride oxidation under different concentrations of $\mathrm{ClO}_{4}{ }^{-}$and $\mathrm{Cl}^{-}$

\begin{tabular}{cccccc}
\hline \hline $\mathrm{ClO}_{4}^{-} \mathrm{i}(\mathrm{mM})$ & $\mathrm{ClO}_{4}^{-} \mathrm{f}(\mathrm{mM})$ & $\mathrm{Cl}_{\mathrm{i}}^{-}(\mathrm{mM})$ & $\mathrm{Cl}_{\mathrm{f}}^{-}(\mathrm{mM})$ & $Q_{t}(\mathrm{C})$ & $Q_{\mathrm{Cl}, \mathrm{r}}(\%)^{*}$ \\
\hline 0.98 & 0.09 & $6.6 \times 10^{3}$ & 0.32 & 2112 & $1.3^{* *}$ \\
0.98 & 0.27 & $6.6 \times 10^{3}$ & 0.31 & 1218 & $1.6^{* *}$ \\
0.48 & 0.04 & 0.29 & 0.12 & 2160 & $2.2^{* * *}$ \\
0.47 & 0.29 & 1.94 & 1.37 & 2160 & $2.7^{* * *}$ \\
$9.8 \times 10^{3}$ & $4.0 \times 10^{4}$ & 2.02 & 0.08 & 4140 & $3.6^{* * *}$ \\
$1.0 \times 10^{3}$ & $5.0 \times 10^{5}$ & 1.89 & 0.07 & 4200 & $3.3^{* * *}$ \\
\hline${ }^{*} \mathrm{Q}$ & & & &
\end{tabular}

${ }^{*} \mathrm{Q}_{\mathrm{Cl}, \mathrm{r}}=\mathrm{Q}_{\mathrm{Cl}} / \mathrm{Q}_{\mathrm{t}} \times 100 ;{ }^{* *} V_{R}=500 \mathrm{~mL} ;{ }^{* * *} V_{R}=800 \mathrm{~mL}$ 
valence at different chloride concentrations and different amounts of charge passed indicate that no bare ZVT particles were being ejected at the pitting site. However, it is also possible to observe a dissolution valence of 4.0 with release of ZVT particles. This could occur if chloride is oxidized at the electrode surface and then the $\mathrm{HOCl}$ produced reacts with the ZVT particles as follows

$$
\begin{gathered}
2 \mathrm{Cl}^{-}=\mathrm{Cl}_{2}+2 \mathrm{e}^{-} \\
\mathrm{Cl}_{2}+\mathrm{H}_{2} \mathrm{O}=\mathrm{HOCl}+\mathrm{HCl} \\
\mathrm{Ti}(0)+2 \mathrm{HOCl}+2 \mathrm{H}^{+}=\mathrm{Ti}^{4+}+2 \mathrm{Cl}^{-}+2 \mathrm{H}_{2} \mathrm{O}
\end{gathered}
$$

The four chloride ions that are oxidized at the electrode to produce two $\mathrm{HOCl}$ required to oxidize one ZVT would cause $4 \mathrm{e}^{-}$to transfer through the electrode, so the measured dissolution valence would be +4 . However, previous results including optical microscopic observations, precipitates observation using scanning electron microscope (SEM) (Fig. 1), and XRD analysis of precipitates (Fig. 2) support the conclusion that ZVT particles were not being ejected from the pitting site. Thus, perchlorate reduction is probably not caused by bare ZVT metal particles ejected from the ZVT electrode.

Fig. 5 shows the molar ratio of ZVT consumed to perchlorate reduced $\left(\Delta \mathrm{Ti}(0) / \Delta \mathrm{ClO}_{4}{ }^{-}\right)$as a function of the amount of charge passed through the electrode for two different initial concentrations of perchlorate. Values of $\Delta \mathrm{Ti}(0) / \Delta \mathrm{ClO}_{4}{ }^{-}$for both initial concentrations gradually increase with increasing electric charge passed. In order to completely reduce one mole of perchlorate to chloride, four moles of $\mathrm{Ti}^{2+}$ and eight moles of $\mathrm{Ti}^{3+}$ are required and most of the data in Fig. 5 lies in the range between these two values. However, data early in the experiments show ratios below 4. This could be caused by the formation of precipitates on the electrodes, which primarily consist of $\mathrm{TiO}_{2}$. Small amounts of these precipitates remained on the electrodes, because they were hard to remove completely, even with repeated cleanup with a plastic brush. The mass of these precipitates on the electrodes would be measured as mass of ZVT and cause the measured changes in ZVT to be too low, resulting in ratios that are too low. Results in Table 2 and Fig. 5 are inconclusive concerning whether Ti(II) or Ti(III) is the primary product of dissolution of ZVT and therefore the most likely reductant for perchlorate. However, there is a hypothesis in the literature that describes formation of uncommon metal ions during electrochemical dissolution of metals (Drazic and Popic 2005, James 1974). This hypothesis applied to the results in Fig. 5 and Table 2 strongly suggests that $\mathrm{Ti}(\mathrm{II})$ is the primary product of the dissolution of ZVT that could be responsible for reduction of perchlorate. The hypothesis is that metals pass through stepwise oxidations during electrochemical metal dissolution.

Suppose that metal has two oxidation states $(+\mathrm{I}$ and $+\mathrm{II})$. The first step in electrochemically dissolving the metal would produce $\mathrm{M}(\mathrm{I})$. Further oxidation of $\mathrm{M}(\mathrm{I})$ to $\mathrm{M}(\mathrm{II})$ could be caused by two pathways. One is a chemical oxidation by an oxidizing agent that is present in solution. The other pathway is further electrochemical oxidation at the anode (metal surface) and depends on M(I) being strongly adsorbed to the anode metal surface (Drazic and Popic 2005). The relative importance of chemical or electrochemical oxidation of $M(\mathrm{I})$ to $M(\mathrm{II})$ is determined by the presence of oxidizing agents and their concentrations. If there are no oxidizing agents or they are present at low concentrations, electrochemical oxidation is predominant and the dissolution valence of the metal would be +2 . However, if there are oxidizing agents present and they exist at high 
concentrations, chemical oxidation is predominant and the dissolution valence of the metal would be less than +2 . Higher concentrations of the oxidizing agent would result in more chemical oxidation of $\mathrm{M}(\mathrm{I})$ and lower dissolution valences that would approach +1 .

If this mechanism is applied to ZVT dissolution, the first step would produce Ti(II), because the lowest oxidation state of titanium metal ion is +2 . Further oxidation of Ti(II) would be caused by reaction at the electrode surface or with dissolved oxidizing agents. The oxidizing agent used in this study is perchlorate, so the chemical oxidation of Ti(II) could be described as follows

$$
4 \mathrm{Ti}^{2+}+\mathrm{ClO}_{4}^{-} \rightarrow 4 \mathrm{TiO}^{2+}+\mathrm{Cl}^{-}
$$

However, it is also possible that electrochemically produced chlorine would oxidize the Ti(II)

$$
\mathrm{Ti}^{2+}+\mathrm{Cl}_{2} \rightarrow \mathrm{Ti}^{4+}+2 \mathrm{Cl}^{-}
$$

The electrochemical oxidation of Ti(II) to Ti(IV) on the surface of an anodically polarized ZVT electrode can be described as follows

$$
\begin{aligned}
& \mathrm{Ti}^{2+} \rightarrow \mathrm{Ti}^{3+}+\mathrm{e}^{-} \\
& \mathrm{Ti}^{3+} \rightarrow \mathrm{Ti}^{4+}+\mathrm{e}^{-}
\end{aligned}
$$

Table 2 shows that the dissolution valence of ZVT gradually decreases from 3.77 to 2.67 when perchlorate concentration increases from $1 \mathrm{mM}$ to $500 \mathrm{mM}$. Increasing perchlorate concentrations would increase the extent of the reaction described by reaction 11 and would result in lowering the dissolution valence. However, when chloride is the only anion present, the reactions shown in reactions 13 and 14 would be predominant and dissolved Ti(II) would tend to be electrochemically oxidized to Ti(III) and Ti(IV), if dissolved Ti(II) is strongly adsorbed on the ZVT surface. This would result in a dissolution valence of +4 in chloride solution. The other explanation is also possible based on chlorine formation and reaction 12. If one mole of ZVT is oxidized to Ti(II), it

Table 2 Observed dissolution valence for pitting corrosion of titanium under different concentrations of $\mathrm{ClO}_{4}^{-}$ and $\mathrm{Cl}^{-}$

\begin{tabular}{ccccc}
\hline \hline Types of anion Concentration $(\mathrm{mM})$ & Total charge $(C)$ & Average weight loss $(\mathrm{mg})$ & Valence \\
\hline 1 & 1000 & 131.6 & $3.77 \pm 0.09$ \\
& 10 & 1000 & 156.8 & $3.17 \pm 0.01$ \\
$\mathrm{ClO}_{4}^{-}$ & 50 & 1000 & 167.3 & $2.97 \pm 0.01$ \\
& 100 & 1000 & 335.9 & $2.95 \pm 0.01$ \\
& 250 & 1000 & 173.1 & $2.87 \pm 0.02$ \\
& 500 & 1000 & 178.60 & $2.78 \pm 0.04$ \\
$\mathrm{Cl}^{-}$ & 10 & 1000 & 186.2 & $2.67 \pm 0.01$ \\
\hline & 100 & 1000 & 120.4 & $4.12 \pm 0.03$ \\
& 2000 & 121.3 & $4.09 \pm 0.01$ \\
& & & 240.06 & $4.13 \pm 0.09$ \\
\hline
\end{tabular}




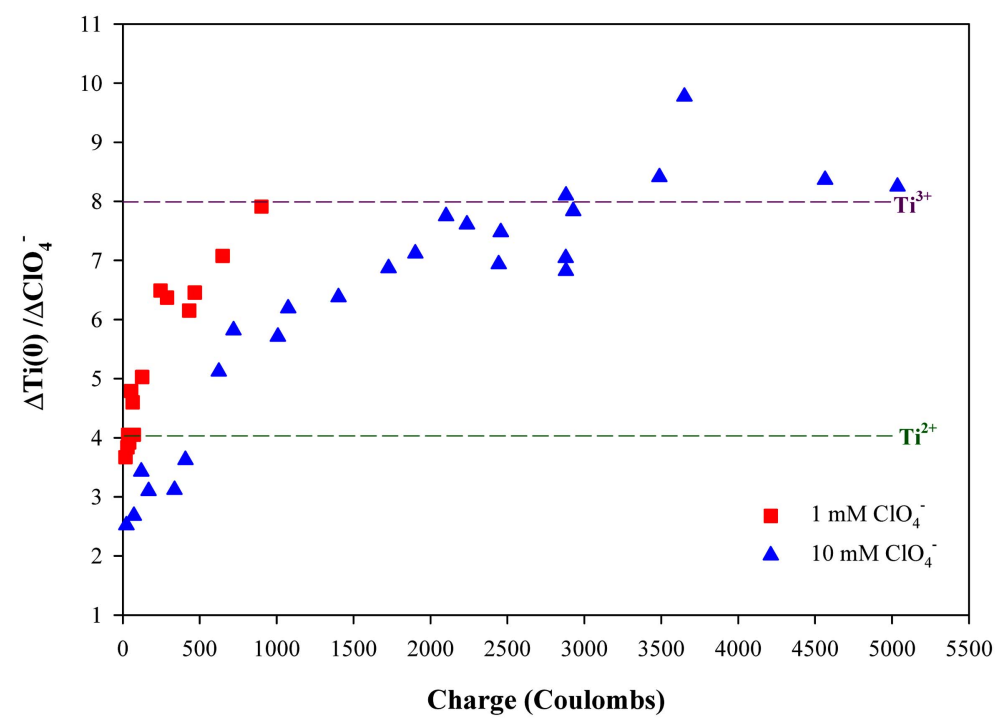

Fig. 5 Molar ratio of titanium consumed to perchlorate removed

will transfer 2 moles of electrons to the electrode. If 2 moles of $\mathrm{Cl}^{-}$are oxidized to chlorine, it will transfer 2 more moles of electrons to the electrode. Then, the Ti(II) can react with the chlorine to produce Ti(IV) and chloride. The net electron transfer for loss of one mole of ZVT is 4 moles (2 moles form production of $\mathrm{Ti}(\mathrm{II})$ and 2 moles from production of chlorine) and the dissolution valence is +4 .

Fig. 5 shows that values of $\Delta \mathrm{Ti}(0) / \Delta \mathrm{ClO}_{4}{ }^{-}$gradually increase with increasing electric charge passed. This is related to the decrease in perchlorate concentration and the increase in chloride concentration over the course of the experiment. The lower concentration of perchlorate would cause the rate of reaction 11 to decrease, while the increasing concentration of chloride would cause the rate of reaction 12 to increase. Therefore, as the amount of charge passed increases, a greater fraction of the Ti(II) would react with chlorine rather than perchlorate, resulting in higher values of $\Delta \operatorname{Ti}(0) / \Delta \mathrm{ClO}_{4}{ }^{-}$. These results indicate that mechanism for perchlorate reduction that is based on formation of transient metal ions fairly well describes experimental results for dissolution of ZVT.

\subsection{Proposal of Ti(II) dissolution mechanism}

Pitting corrosion on a metal surface develops unique environments inside the pits, such as higher concentrations of aggressive anions and of metal ions than in the external solution. These unique environments inside the pitting sites might be responsible for Ti(II) dissolution and perchlorate reduction during the pitting corrosion of ZVT. In general, metal dissolution is described by a hydroxo-ligand mechanism (Kedda 2002).

$$
\begin{gathered}
\mathrm{M}+\mathrm{H}_{2} \mathrm{O} \rightarrow \mathrm{MOH}_{\mathrm{ads}}+\mathrm{H}^{+}+\mathrm{e}^{-} \\
\mathrm{MOH}_{\mathrm{ads}} \rightarrow \mathrm{MOH}_{\mathrm{aq}}^{+}+\mathrm{e}^{-}
\end{gathered}
$$




$$
\mathrm{MOH}^{+}+\mathrm{H}^{+} \rightarrow \mathrm{M}^{2+}+\mathrm{H}_{2} \mathrm{O}
$$

However, several studies reported that aggressive anions are involved in metal dissolution during pitting corrosion and electrochemical metal dissolution (Arvia and Podesta 1968, Chin and Nobe 1972, Eichkorn et al. 1968, Hackerma et al. 1966, Iofa and Batrakov 1964, Kim and Pyun 1995, Kolotyrkin 1961, Kuo and Nobe 1978, Macfarlane and Smedley 1986, Mccaffer and Hackerma 1972, Murakawa et al. 1967, Pyun and Lee 1995, Smart et al. 1993). These studies proposed that aggressive anions are adsorbed on the bare metal surface during pitting corrosion and stimulate metal dissolution. Two types of models were proposed to describe how anions are involved in metal dissolution: 1) indirect and 2) direct participation models. For the indirect participation model, the aggressive anions stimulate metal dissolution after localized breakdown of the surface oxide film, but the metal is dissolved as a hydroxo-metal complex (Arvia and Podesta 1968, Eichkorn et al. 1968, Hackerma et al. 1966, Mccaffer and Hackerma 1972, Murakawa et al. 1967). If ZVT is dissolved with indirect participation of anions in the dissolution process during pitting corrosion, ZVT would be dissolved as shown below (Arvia and Podesta 1968).

$$
\begin{gathered}
\mathrm{Ti}+\mathrm{X}^{-} \leftrightarrow \mathrm{TiX}_{\text {ads }}^{-} \\
\mathrm{TiX}_{\text {ads }}^{-}+\mathrm{H}_{2} \mathrm{O} \rightarrow \mathrm{TiOH}^{-}{ }_{\text {ads }}+\mathrm{H}^{+}+\mathrm{X}^{-} \\
\mathrm{TiOH}^{-}{ }_{\text {ads }} \leftrightarrow \mathrm{Ti}^{2+}+\mathrm{OH}^{-}+2 \mathrm{e}^{-}
\end{gathered}
$$

where $\mathrm{X}^{-}$is an aggressive anion that induces pitting corrosion. The direct participation model proposes that the anions not only prompt metal dissolution, but also leave the metal surface by forming complexes with dissolved metal ions (Chin and Nobe 1972, Iofa and Batrakov 1964, Kim and Pyun 1995, Kolotyrkin 1961, Kuo and Nobe 1978, Macfarlane and Smedley 1986, Pyun and Lee 1995). If ZVT is dissolved with direct participation of anions in the dissolution process during pitting corrosion, ZVT would be dissolved through three possible pathways and they are presented below (Kuo and Nobe 1978)

OH stimulated dissolution

$$
\begin{gathered}
\mathrm{Ti}+\mathrm{H}_{2} \mathrm{O} \leftrightarrow \mathrm{TiOH}_{\mathrm{ads}}+\mathrm{H}^{+}+\mathrm{e}^{-} \\
\mathrm{TiOH}_{\mathrm{ads}} \rightarrow \mathrm{TiOH}^{+}+\mathrm{e}^{-} \\
\mathrm{TiOH}^{+}+\mathrm{H}^{+} \leftrightarrow \mathrm{Ti}^{2+}+\mathrm{H}_{2} \mathrm{O}
\end{gathered}
$$

$X^{-}$stimulated dissolution

$$
\begin{gathered}
\mathrm{Ti}+\mathrm{H}_{2} \mathrm{O}+\mathrm{X}^{-} \leftrightarrow \mathrm{TiXOH}^{-}{ }_{\text {ads }}+\mathrm{H}^{+}+\mathrm{e}^{-} \\
\mathrm{TiXOH}{ }_{\text {ads }}
\end{gathered}
$$


$H^{+}-X^{-}$stimulated dissolution

$$
\begin{gathered}
\mathrm{Ti}+\mathrm{H}_{2} \mathrm{O}+\mathrm{X}^{-} \leftrightarrow \mathrm{TiX}_{\mathrm{ads}}+\mathrm{H}_{2} \mathrm{O}+\mathrm{e}^{-} \\
\mathrm{TiX}_{\text {ads }}+\mathrm{H}^{+} \rightarrow \mathrm{TiXH}_{\text {ads }}^{+} \\
\mathrm{TiXH}_{\text {ads }}^{+}+\mathrm{X}^{-} \leftrightarrow \mathrm{TiX}_{2}+\mathrm{H}^{+}+\mathrm{e}^{-} \\
\operatorname{TiX}_{2} \leftrightarrow \mathrm{Ti}^{2+}+2 \mathrm{X}^{-}
\end{gathered}
$$

The relative importance of $\mathrm{OH}^{-}, \mathrm{X}^{-}$and $\mathrm{H}^{+}-\mathrm{X}^{-}$stimulated dissolutions is determined by the presence of aggressive anions and solution $\mathrm{pH}$. In general, reactions 21-23 might be predominant if ZVT undergoes dissolution with low concentrations of aggressive ion. However, when solution contains higher concentrations of aggressive anions, the ZVT would tend to undergo dissolution by reactions 24-26. However, if the solution contains higher concentrations of aggressive anions at lower solution $\mathrm{pH}, \mathrm{ZVT}$ dissolution would tend to occur by reactions 27-30.

During pitting corrosion of ZVT, considerable enrichments of dissolved metal ions and anions in the pit cause a salt film to be developed at the bottom of the pit. The salt film works as a barrier and limits transportation of anions and dissolved metal ions to solution by separating bare metal surface from solution (Beck 1973a, 1973b, Grimm et al. 1992, Mankowski and Szklarskasmialowska 1977). It has been reported that the titanium salt film forms within $10^{-5}$ to $10^{-3} \mathrm{~s}$ following pit nucleation and its thickness ranges from 2 to $10 \mathrm{~nm}$ during pitting corrosion (Alkire et al. 1978). However, the salt film has a very short life that lasts several seconds after interruption of current (Danielson 1988). Thus, it is hard to detect physical properties of a salt film. Beck (1973a, b) assumed that salt films in pits of corroding ZVT form compact films. However, for other metals, several studies postulated that the salt film is either porous (Beck 1982, Clerc and Landolt 1988, Danielson 1988, Hunkeler et al. 1987) or contains both porous and compact film layers (Beck 1985, Grimm et al. 1992).

When ZVT undergoes dissolution to Ti(II), aggressive anions are transported from solution to the bare ZVT surface through the salt film in order to balance the positive charge and concentrated at the interface between the bare ZVT and salt film (Okada 1984). The dissolution of ZVT would be accelerated by the adsorption of the aggressive anion on bare ZVT. If ZVT is dissolved with indirect participation of anions in the dissolution process (Eqs. (18)-(20)), dissolved $\mathrm{Ti}^{2+}$ would reduce perchlorate at the interface between the bare ZVT and salt film. However, if ZVT is dissolved with direct participation of anions, ZVT would be dissolved by forming Ti(II) and anion complexes. Since the $\mathrm{pH}$ in the pit is higher than $\mathrm{pH}$ in solution due to electrolytic migration of $\mathrm{H}^{+}$ away from the bare metal surface (Beck 1982, Danielson 1988), the formation of titanium anion complexes might occur as shown in Eqs. (24)-(26), rather than by Eqs. (27)-(30). Then, bare ZVT would be dissolved as $\mathrm{Ti}\left(\mathrm{ClO}_{4}\right) \mathrm{OH}$ for solutions that contain perchlorate. This dissolved complex of $\mathrm{Ti}(\mathrm{II})$ and perchlorate provides the opportunity for an oxidation/reduction reaction to occur that would reduce perchlorate and oxidize $\mathrm{Ti}^{2+}$ to $\mathrm{TiO}^{2+}$. However, for solutions that contain chloride without perchlorate, $\mathrm{TiClOH}$ would be formed and would dissociate to $\mathrm{Ti}^{2+}$ and $\mathrm{Cl}^{-}$without a redox reaction occurring. As the salt film works as a barrier that limits transport of dissolved metal ions to the solution, a high concentration of $\mathrm{Ti}^{2+}$ produced by dissociation of $\mathrm{TiClOH}$ (direct participation model) or dissolution of ZVT to $\mathrm{Ti}^{2+}$ (indirect participation model) would accumulate at the interface 
between the salt film and bare ZVT. The majority of $\mathrm{Ti}^{2+}$ would be either electrochemically or chemically oxidized to Ti(IV). The electrochemical oxidation of $\mathrm{Ti}^{2+}$ could occur on the bare ZVT surface or on surface of the salt film, which is plausible because of a low potential drop across the salt film. The chemical oxidation of $\mathrm{Ti}^{2+}$ could be developed by oxidizing agents present in solution, such as water or chlorine that is produced by electrochemical oxidation of chloride. The Ti(IV) produced by this oxidation would regenerate the salt film and keep the bare ZVT separate from the bulk solution in the pit.

\section{Conclusions}

It has been shown that perchlorate is rapidly reduced to chloride during pitting corrosion of titanium. Three possible mechanisms (ejection of bare ZVT particles, high ohmic potential drop across an oxide film, and formation of partially oxidized titanium metal ions) were examined and a mechanism involving Ti(II) as a partially oxidized ion is proposed as the one that best describes experimental observations. The rate of perchlorate reduction is sufficiently rapid for application as a treatment process. However, there are several limitations that currently restrict its application to treatment systems. These limitations are: 1) high energy costs, 2) chloride oxidation, and 3) unwanted titanium dissolution during treatment of trace levels of perchlorate. These limitations seem to be caused by different problems. However, these restrictions are associated with the high potential (over $12 \mathrm{~V}$ ) required to develop the pitting corrosion on titanium. Thus, this high pitting potential causes the high energy cost and promotes oxidation of chloride to chlorine. Moreover, high electrical energy input dissolves more titanium than needed to reduce perchlorate. Therefore, lowering the pitting potential of titanium is a key to overcoming the high cost of the electrochemical titanium process and making it feasible for field application. Furthermore, it would be advantageous for field applications if the titanium were to undergo dissolution without any electrical energy input.

\section{Acknowledgements}

This article is dedicated to Dr. Timothy A. Kramer, who died in a plane crash on December 10, 2006. The authors wish to extend faithful thanks and appreciations to him. This project has been supported with funds from the Association of American Railroads (AAR) and from the State of Texas as part of the program of the Texas Hazardous Waste Research Center. We appreciate that Texas A\&M University at Qatar (TAMUQ) has provided the opportunity to prepare this paper and to work on planning future research.

\section{References}

Alkire, R., Ernsberger, D. and Beck, T.R. (1978), "Occurrence of salt films during repassivation of newly generated metal-surfaces", J. Electrochem. Soc., 125(9), 1382-1388.

Amadei, G.A. and Earley, J.E. (2001), "Effect of some macrocyclic ligands on the rate of reduction of perchlorate ion by titanium (III)", Croat. Chem. Acta, 74(3), 601-606.

Arvia, A.J. and Podesta, J.J. (1968), "Kinetics of anodic dissolution of active iron in acid solutions containing high concentration of halides", Corros. Sci., 8(3), 203-205.

Basame, S.B. and White, H.S. (2000), "Pitting corrosion of titanium - The relationship between fitting potential 
and competitive anion adsorption at the oxide film/electrolyte interface", J. Electrochem. Soc., 147(4), 13761381.

Beck, T.R. (1973a), "Pitting of titanium. 1. Titanium-foil experiments", J. Electrochem. Soc., 120(10), 13101316.

Beck, T.R. (1973b), "Pitting of titanium. 2. One-dimensional pit experiments", J. Electrochem. Soc., 120(10), 1317-1324.

Beck, T.R. (1982), "Formation of salt films during passivation of iron", J. Electrochem. Soc., 129(11), 24122418.

Beck, T.R. (1984), "Salt film formation during corrosion of aluminum", Electrochim. Acta, 29(4), 485-491.

Beck, T.R. (1985), "Electrical-properties of aluminum-chloride film on corroding aluminum", Electrochim. Acta, 30(6), 725-730.

Beck, T.R. and Alkire, R.C. (1979), "Occurrence of salt films during initiation and growth of corrosion pits", $J$. Electrochem. Soc., 126(10), 1662-1666.

Chin, R.J. and Nobe, K. (1972), "Electrodissolution kinetics of iron in chloride solutions. 3. Acidic solutions", J. Electrochem. Soc., 119(11), 1457-1461.

Clerc, C. and Landolt, D. (1988), "Ac impedance study of anodic films on nickel in LiCl”, Electrochim. Acta, 33(7), 859-871.

Cotton, F.A., Wilkinson, G. and Gaus, P.L. (1995), Basic Inorganic Chemistry, 3rd Edition, John Wiley \& Sons Inc., New York, NY.

Danielson, M.J. (1988), "Transport-properties of salt films on nickel in 0.5N HCl”, J. Electrochem. Soc., 135(8), C354-C354.

Delplancke, J.L., Degrez, M., Fontana, A. and Winand, R. (1982), "Self-colour anodizing of titanium", Surf. Technol., 16(2), 153-162.

Delplancke, J.L. and Winand, R. (1988), "Galvanostatic anodization of titanium-I. Structures and compositions of the anodic films", Electrochim. Acta, 33(11), 1539-1549.

Drazic, D. and Popic, J. (2005), “Anomalous dissolution of metals and chemical corrosion”, J. Serb. Chem. Soc., 70(3), 489-511.

Earley, J.E., Tofan, D.C. and Amadei, G.A. (2000), Perchlorate in the Environment, Kluwer/Plenum, New York, NY.

Eichkorn, G., Lorenz, W.J., Albert, L. and Fischer, H. (1968), "Influence of surface activity on anode dissolution mechanisms of iron in acid solutions", Electrochim. Acta, 13(2), 183-186.

Emsley, J. (1991), The elements, 2nd Edition, Clarendon Press, Oxford, UK.

EPA. (2012), http://www.regulations.gov/\#!searchResults;rpp=10;po=0;s=EPA-HQ-OW-2008-0692.

Espenson, J.H. (2000), The problem and perversity of perchlorate, Kluwer/Plenum, New York, NY.

Farrell, J., Kason, M., Melitas, N. and Li, T. (2000), "Investigation of the long-term performance of zero-valent iron for reductive dechlorination of trichloroethylene", Environ. Sci. Technol., 34(3), 514-521.

Fontana, M.G. (1986), Corrosion Engineering, 3rd Edition, McGraw-Hill Book Company, New York, NY.

Gaspar, D.J., Lea, A.S., Engelhard, M.H., Baer, D.R., Miehr, R. and Tratnyek, P.G. (2002), "Evidence for localization of reaction upon reduction of carbon tetrachloride by granular Iron", Langmuir, 18(20), 76887693.

Gaul, E. (1993), "Coloring titanium and related metals by electrochemical oxidation”, J. Chem. Educ., 70(3), 176-178.

Geiger, C.L., Ruiz, N.E., Clausen, C.A., Reinhart, D.R. and Quinn, J.W. (2002), "Ultrasound pretreatment of elemental iron: Kinetic studies of dehalogenation reaction enhancement and surface effects", Water Res., 36(5), 1342-1350.

Gotpagar, J., Lyuksyutov, S., Cohn, R., Grulke, E. and Bhattacharyya, D. (1999), "Reductive dehalogenation of trichloroethylene with zero-valent iron: Surface profiling microscopy and rate enhancement studies", Langmuir, 15(24), 8412-8420.

Grimm, R.D., West, A.C. and Landolt, D. (1992), "Ac impedance study of anodically formed salt films on iron in chloride solution", J. Electrochem. Soc., 139(6), 1622-1629.

Gu, B., Bonnesen, P., Sloop, F. and Brown, G. (2006), Titanium Catalyzed Perchlorate Reduction and Applications Perchlorate, Springer, US. 
Guleryuz, H. and Cimenoglu, H. (2004), "Effect of thermal oxidation on corrosion and corrosion-wear behaviour of a Ti-6A1-4V alloy", Biomaterials, 25(16), 3325-3333.

Hackerma, N., Snavely, E.S. and Payne, J.S. (1966), "Effects of anions on corrosion inhibition by organic compounds", J. Electrochem. Soc., 113(7), 677-681.

Hernandez, R., Zappi, M. and Kuo, C.H. (2004), "Chloride effect on TNT degradation by zerovalent iron or zinc during water treatment", Environ. Sci. Technol., 38(19), 5157-5163.

Hrapovic, S., Luan, B.L., D'Amours, M., Vatankhah, G. and Jerkiewicz, G. (2001), "Morphology, chemical composition, and electrochemical characteristics of colored titanium passive layers", Langmuir, 17(10), 30513060 .

Hunkeler, F., Krolikowski, A. and Bohni, H. (1987), “A study of the solid salt film on nickel and stainless-steel”, Electrochim. Acta, 32(4), 615-620.

Iofa, Z.R. and Batrakov, V.V. (1964), "Influence of anion adsorption on the action of inhibitors on the acid corrosion of iron and cobalt", Electrochim. Acta, 9(12),1645-1653.

Isaacs, H.S. (1973), "Behavior of resistive layers in localized corrosion of stainless-steel", J. Electrochem. Soc., 120(11), 1456-1462.

Ivanenko, V.I., Udalova, I.A., Lokshin, E.P. and Kravstov, V.I. (2001), "Potentiometric study of reactions of titanium complexes in phosphate-perchlorate acid solutions", Russ. J. Electrochem. (Translation of Elektrokhimiya), 37(5), 530-535.

James, W. (1974), Advances in Corrosion Science and Technology, Plenum Press, New York and London.

Kedda, M. (2002), Corrosion Mechanisms in Theory abd Practice, Marcel Dekker, New York, NY.

Kim, J.D. and Pyun, S.I. (1995), "Effects of electrolyte-composition and applied potential on the repassivation kinetics of pure aluminum", Electrochim. Acta, 40(12), 1863-1869.

Kölle, U. and Kölle, P. (2003), "Aqueous chemistry of titanium(II) species”, Angew. Chem. Int. Edit., 42(37), 4540-4542.

Kolotyrkin, J.M. (1961), "Effects of anions on the dissolution kinetics of metals", J. Electrochem. Soc., 108(3), 209-216.

Kuo, H.C. and Nobe, K. (1978), "Electrodissolution kinetics of iron in chloride solutions. 6. concentrated acidic solutions", J. Electrochem. Soc., 125(6), 853-860.

Lang, G.G. and Horanyi, G. (2003), "Some interesting aspects of the catalytic and electrocatalytic reduction of perchlorate ions", J. Electroanal. Chem., 552,197-211.

Lee, C. (2007), Perchlorate reduction during electrochemically induced pitting corrosion of zero-valent titanium, Texas A\&M University, College Station, TX.

Lee, C., Batchelor, B., Park, S.H., Han, D.S., Abdel-Wahab, A. and Kramer, T.A. (2011), "Perchlorate reduction during electrochemically induced pitting corrosion of zero-valent titanium (ZVT)", J. Hazard. Mater., 197,183189.

Lien, H.L., Yu, C.C. and Lee, Y.C. (2010), "Perchlorate removal by acidified zero-valent aluminum and aluminum hydroxide", Chemosphere, 80(8), 888-893.

Macfarlane, D.R. and Smedley, S.I. (1986), "The dissolution mechanism of iron in chloride solutions", $J$. Electrochem. Soc., 133(11), 2240-2244.

Mankowski, J. and Szklarskasmialowska, Z. (1977), "Effect of specimen position on shape of corrosion pits in an austenitic stainless-steel", Corros. Sci., 17(9), 725-735.

Mathieu, J.B. and Landolt, D. (1978), "Electropolishing of titanium in perchloric acid-acetic acid solution. 2. Polarization behavior and stoichiometry", J. Electrochem. Soc., 125(7), 1044-1049.

Mathieu, J.B., Mathieu, H.J. and Landolt, D. (1978), "Electropolishing of titanium in perchloric acid-acetic acid solution. 1. Anguer-electron spectroscopy study of anodic films", J. Electrochem. Soc., 125(7), 1039-1043.

Mccaffer, E. and Hackerma, N. (1972), "Kinetics of iron corrosion in concentrated acidic chloride solutions", $J$. Electrochem. Soc., 119(8), 999-1009.

Moore, A.M., DeLeon, C.H. and Young, T.M. (2003), "Rate and extent of aqueous perchlorate removal by iron surfaces", Environ. Sci. Technol., 37(14), 3189-3198.

Murakawa, T., Nagaura, S. and Hackerma, N. (1967), "Coverage of iron surface by organic compounds and anions in acid solutions", Corros. Sci., 7(2), 79-89.

Okada, T. (1984), "Considerations of the stability of pit repassivation during pitting corrosion of passive metals", 
J. Electrochem. Soc., 131(5), 1026-1032.

Palit, G.C. and Gadiyar, H.S. (1987), "Pitting corrosion of zirconium in chloride solution", Corrosion, 43(3), 140148.

Park, Y.J., Shin, K.H. and Song, H.J. (2007), "Effects of anodizing conditions on bond strength of anodically oxidized film to titanium substrate", Appl. Surf. Sci., 253(14), 6013-6018.

Pickering, H.W. (1987), "A critical review of IR drops and electrode potentials within pits, crevices, and cracks", Proceedings of the Second International Conference on Localized Corrosion, Orlando, June.

Pourbaix, M. (1966), Atlas of Electrochemical Equilibria in Aqueous Solutions, 1st Edition, Pergamon Press Ltd., New York, NY.

Prinz, H. and Strehblow, H.H. (1998), "Investigations on pitting corrosion of iron in perchlorate electrolytes", Corros. Sci., 40(10), 1671-1683.

Pyun, S.I. and Lee, E.J. (1995), "Effect of halide ion and applied potential on repassivation behavior of Al1wt.percent-Si-0.5wt.percent-Cu alloy", Electrochim. Acta, 40(12), 1963-1970.

Scherer, M.M., Westall, J.C. and Tratnyek, P.G. (1999), "The kinetics of nitro reduction by iron metal: A case of mixed control", Symposia Paper of Interfacial and Colloidal Phenomena in Aquatic Environments Reactions at Surfaces, Anaheim, March.

Smart, N.G., Gamboaaldeco, M. and Bockris, J.O. (1993), "Corrosion mechanisms of iron in concentrated acidic zinc-chloride media", Corros. Sci., 34(5), 759-777.

Sridhar, N. and Dunn, D.S. (1997), "In situ study of salt film stability in simulated pits of nickel by Raman and electrochemical impedance spectroscopies", J. Electrochem. Soc., 144(12), 4243-4253.

Srinivasan, R. and Sorial, G.A. (2009), "Treatment of perchlorate in drinking water: A critical review", Sep. Purif. Technol., 69(1), 7-21.

Strehblow, H.H. and Ives, M.B. (1976), "On the electrochemical conditions within small pits", Corros. Sci., 16(5), 317-318.

Szklarska-Smialowska, Z. (1986), Pitting Corrosion of Metals, National Association of Corrosion Engineers, Houston, TX

Wang, C., Huang, Z., Lipincott, L. and Meng, X. (2010), "Rapid Ti(III) reduction of perchlorate in the presence of beta-alanine: Kinetics, pH effect, complex formation, and beta-alanine effect", J. Hazard. Mater., 175(13), $159-164$.

Wang, D.M. and Huang, C.P. (2008), "Electrodialytically assisted catalytic reduction (EDACR) of perchlorate in dilute aqueous solutions", Sep. Purif. Technol., 59(3), 333-341.

Wang, D.M., Huang, C.P., Chen, J.G., Lin, H.Y. and Shah, S.I. (2007), "Reduction of perchlorate in dilute aqueous solutions over monometallic nano-catalysts: Exemplified by tin", Sep. Purif. Technol., 58(1), 129-137.

Wang, D.M., Lin, H.Y., Shah, S.I., Ni, C.Y. and Huang, C.P. (2009), "Indirect electrochemical reduction of perchlorate and nitrate in dilute aqueous solutions at the Ti-water interface", Sep. Purif. Technol., 67(2), 127134.

Webelements periodic table (2007), http://www.webelements.com/.

Yan, W. and Wang, X.X. (2004), "Surface hardening of titanium by thermal oxidation", J. Mater. Sci., 39(16-17), 5583-5585. 